\title{
Book Review: International Telecommunications Law and Policy
}

Uchenna Jerome Orji, International Telecommunications Law and Policy. Newcastle upon Tyne, UK: Cambridge Scholars Publishing, 2018, 425 pages, $£ 74.99$ (hardcover). ISBN-13: 978-1-5275-0836-1; ISBN-10: 1-5275-0836-6

\section{Reviewer: Pontian N. Okoli}

Lecturer, School of Law, University of Stirling, Scotland

(iD) https://orcid.org/0000-0003-2704-4161

\section{Keywords}

telecommunications, law, policy, regulations, institiutions, history, international, Africa

DOI: https://doi.org/10.23962/10539/29190

\section{Recommended citation}

Okoli, P. N. (2020). Book review: International telecommunications law and policy. The African Journal of Information and Communication (AJIC), 25, 1-5.

https://doi.org/10.23962/10539/29190

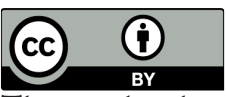

This article is licensed under a Creative Commons Attribution 4.0 International (CC BY 4.0) licence: https://creativecommons.org/licenses/by/4.0

This comprehensive volume by Nigerian legal academic Orji engages with the international, African continental, and African regional regimes that govern telecommunications regulation. The international organisations covered are the United Nations (UN), the International Telecommunication Union (ITU), and the World Trade Organisation (WTO). The African continental organisations dealt with are the African Union (AU), the African Telecommunications Union (ATU), the UN Economic Commission for Africa (UNECA), and the Regional African Satellite Communication Organisation (RASCOM). African regional entities considered are the Economic Community of West African States (ECOWAS), the Common Market for Eastern and Southern Africa (COMESA), the Economic Community of Central African States (ECCAS), the Economic and Monetary Community of Central Africa (CEMAC), the East African Community (EAC), and the Southern African Development Community (SADC).

The first chapter traces the historical origins of telecommunications, the evolution of telecommunications, the implications of various technologies for law and policy, and the sources of international telecommunications law. This chapter provides an 
important introductory context that facilitates engagement with the contents of the 10 chapters that follow.

The second chapter provides a discussion of international telecommunication regimes within the UN framework, including conventions on the law of the seae.g., the UN Convention on the Law of the Sea (UNCLOS), the Convention for the Protection of Telegraph Cables, and the Convention on the Continental Shelf-and on international space law (e.g., the Outer Space Treaty). In the context of UNCLOS, Orji argues for expansion of the convention's limited application of universal jurisdiction - such that all states linked to submarine fibre optic telecommunications cables would be required to establish adequate measures, including penal sanctions, to deter intentional cable damage in their territorial waters (pp. 37-39). This critical treatment of the provisions of UNCLOS is a good precursor to the author's discussion of the Outer Space Treaty (p. 45), which he critiques in terms of, inter alia, definitional inadequacies and the consequences of "orbital debris".

Chapters 3 and 4 provide important institutional insights. Chapter 3 discusses the ITU and the obligations of its Member States, including obligations concerning installation and operation of telecommunication or radio services. There is an illuminating discussion of the no-harm obligation in international law (pp. 7374). The author argues that the no-harm obligation arises from "the ITU's early recognition of the interconnectedness of national telecommunication networks, and the equal rights of States to establish and operate telecommunications installations without interference from either State or non-State actors", and further links the noharm rule to international law principles on state responsibility as recognised in the Trail Smelter ${ }^{1}$ and Corfu Channel ${ }^{2}$ cases.

Chapter 4 arguably provides even better engagement with institutional frameworks, through a discussion of the ITU's International Telecommunication Regulations (ITRs). In examining the proposals of various state parties during the review of the ITRs at the ITU's 2012 World Conference on International Telecommunications (WCIT), the author provides insights into the socio-political underpinnings of certain national policy approaches to international telecommunications. Orji also identifies key factors that influenced ITU Member States' proposals for ITR treatment of concerns over the United States' perceived dominance, at the time, of the multi-stakeholder internet governance structure (the non-governmental Internet Corporation for Assigned Names and Numbers (ICANN); the perceived internet governance agendas of countries such as China, Russia and the Arab states; and questions on the contemporary relevance of the ITRs for global telecommunications governance. Such factors, Orij contends, were to a large extent responsible for

1 Trail Smelter Arbitration (United States v Canada), 3 UNRIAA, p. 1905, 1952.

2 Corfu Channel Case (United Kingdom v Albania); Merits, International Court of Justice (ICJ), 9 April 1949. 
impeding consensus on the ITRs at the 2012 WCIT. The author points out that high levels of contestation are nothing new in international telecommunications negotiations, and that, from the 2012 ITU WCIT onwards, "[i]nternet governance issues would continue to remain a source of contention amongst ITU Member States" (p. 127). These views provide a helpful foundation for the next chapter.

In chapter 5, while analysing several provisions of the 2012 ITRs, Orji revisits some Member State arguments made at the 2012 WCIT, including US arguments regarding obligations on Member States to ensure the security of international telecommunication networks, ${ }^{3}$ and regarding the inclusion of spam control provisions. ${ }^{4}$ The US, citing security concerns, contended that the ITU and the ITRs were not the appropriate venue or framework, respectively. Orji provides practical insights into the political and international security influences on the US position, presenting a balanced scholarly analysis with a presentation of the author's critique as well as critiques by other scholars (pp. 149-154). In respect of cybersecurity, Orji argues that "the ITU may provide a broader platform that will accommodate the perceived interests of developing countries that are opposed to the Council of Europe's Convention on Cybercrime" (p. 151), thus offering the real possibility of attaining a global cybersecurity regime. However, the author argues there is a need to first address the dualism of the ITR framework whereby countries are bound by either the 2012 ITRs or the 1988 ITRs (i.e., if they have not accepted the former). Orji argues that the fragmenting effects of such dualism could be addressed if Member States were to use the ITRs' special arrangements regime to negotiate mutual bilateral or multilateral telecommunication agreements, thus mitigating the perceived effects of dualism on international business conditions and practices in the telecommunications industry.

Chapter 6 continues the exploration of global efforts at harmonised telecommunications law and policy. Orji analyses the basic principles of the International Radio Regulations and discusses the challenge posed by the over-filing of requests for orbital slots for satellite systems ("paper satellites"), arguing that such challenges mean that the Radio Regulations remain relevant (p. 179). He traces the history of the Radio Regulations to the effects of Marconi's patent monopoly on wireless telegraphy and the tragedy of the sinking of the Titanic. Arguably, according to the author, it took the sinking of the Titanic in 1912 to force reconsideration of the inability to reach consensus, at the first International Radiotelegraph Convention in Berlin in 1906, with respect to intercommunication of radio systems (p. 173).

In chapter 7, the author discusses the WTO's telecommunications regulatory regime within the context of the General Agreement on Trade in Services (GATS). The GATS, inspired by the General Agreement on Tariffs and Trade (GATT), came into 
force in 1995 and has promoted trade and development partly through a liberalisation of relevant national trade laws and policies of Member States. However, international regimes such as the GATS do not always guarantee an application on national levels, as countries can also regulate the supply of services. In this context, the author examines the domestic frameworks of countries including the United States, the United Kingdom and Nigeria, in order to explore how the GATS and relevant WTO agreements may be given effect either directly (p. 226) or indirectly (p. 229).

Orji introduces a robust African perspective in chapter 8. In examining telecommunications policies within relevant legal and institutional frameworks, including the AU, he considers the challenges that must be overcome if Africa is to leverage its unprecedented growth in the penetration of mobile telecommunications. The AU Commission's initiatives on telecommunications regulatory harmonisation include the AU Division of Information Society; the Reference Framework for the Harmonization of Telecommunication and ICT Policies and Regulation in Africa; the Comprehensive Continental ICT Strategy for Africa; and the New Partnership for Africa's Development's (NEPAD) Protocol on High Level Policy and Regulatory Framework Broadband ICT Infrastructure for Eastern and Southern Africa (Kigali Protocol). In identifying the impediments to harmonisation in Africa, Orji points out that the sub-regional intergovernmental bodies do not necessarily support harmonisation. The author correctly points to the need for integration of the efforts of sub-regional institutions (p. 276), but could have gone further to examine how such integration could be attained, given that the $\mathrm{AU}$ is apparently unable to provide effective coordination of sub-regional efforts-a task made complicated by, inter alia, "diverse legal traditions" (p. 275). This potential gap does not detract from the persuasive arguments presented in favour of harmonisation, which factor in the challenges that exist and contextualise the current potential for attainment.

In chapter 9, the author discusses the ATU, the AU, RASCOM, and African regional telecommunication harmonisation initiatives such as the African Information Society Initiative and the African Regional Action Plan on the Knowledge Economy. He identifies the challenges faced by the ATU in respect of, inter alia, poor funding and the ATU's under-utilisation in the development and implementation of harmonisation initiatives. Orji recommends that the AU increase utilisation of the ATU for harmonisation efforts, and that the ATU improve awareness of its programmes and their implications for development on the continent.

Chapter 10 focuses on the ECOWAS telecommunication regimes. Orji analyses several aspects of the ECOWAS Telecommunications Package, including legal frameworks on interconnection of ICT networks; services; service providers; and the management of radio frequency spectrum. The author also gives consideration to the West African Telecommunications Regulators Assembly (WATRA), and explores challenges to regional telecommunications regulation. This discussion resonates with 
the analysis provided in Chapter 9 regarding challenges to harmonisation in Africa. Once more, the author highlights the potential for harmonisation, this time through the instrumentality of WATRA. This largely untapped potential is given further detailed consideration in the final chapter, Chapter 11, where Orji provides insights into other sub-regional efforts in Southern, East and Central Africa. In the Southern African context, for example, he argues that "SADC represents at least three main legal traditions, namely: the Common Law, Roman-Dutch Law and Civil Law" (p. 366). He further argues that these variations in legal systems within the region create impediments to the harmonisation of telecommunications law and policies. While there is scope for debate on this matter, the author has succeeded in articulating his views in a cogent manner, which is of great practical benefit to the body of academic literature in this area. Other aspects of Orji's analysis of sub-regional organisations include treatment of COMESA and the EAC. He concludes that, in respect of facilitating regional economic integration, "to a large extent, the $[. .$.$] challenges$ appear similar across all the sub-regions [...]" (p. 389).

A major strength of this book lies in the scope of its coverage. In an area where there is a paucity of academic literature, especially literature providing in-depth consideration of African realities, this volume is a commendable effort that scholars will find to be a good basis for further research. The international comparative legal analysis makes the book potentially appealing to scholars in a variety of jurisdictions around the world. Beyond scholarly circles, the book should also be useful to lawyers, regulators, policymakers, and potential investors. 